\title{
Understanding and Measuring Child Well-Being in the Region of Attica, Greece: Round Three
}

\author{
Eirini Leriou ${ }^{1,2} \mathbb{D} \cdot$ Andreas Kollias $^{3} \cdot$ Anna Anastasopoulou $^{3} \cdot$ \\ Aristeidis Katranis ${ }^{3}$
}

Accepted: 19 December 2021/Published online: 28 January 2022

(c) The Author(s), under exclusive licence to Springer Nature B.V. 2022

\begin{abstract}
This research paper aims to present the results of implementing a new multi-dimensional and cumulative tool that records child well-being, in the 2 nd semester of the school year 2019-2020, which is the third round of an ongoing research. It also presents the results of the same year as a whole, in order to investigate the impact of the COVID-19 pandemic on the well-being of children. The tool was applied in Attica through questionnaires, addressing 22 public schools and three support centers of the organization, The Smile of the Child (25 units in total). The number of children in the sample was 560, belonging to three distinct school categories. The results of the 2 nd semester were mapped out in seven clusters. The analysis of the results of the school year 2019-2020 as a whole was applied on a sample of 1,731 children; in other words, it incorporated almost the entire sample of the surveys conducted in the 1st and 2nd semesters. Finally, an action plan, based on the legal framework, focusing on mitigating the negative effects of the pandemic on child well-being is suggested.
\end{abstract}

Keywords COVID-19 · Indicators · Child well-being · Welfare economics · Legal framework - Social protection

Eirini Leriou

eirinileriou@panteion.gr

1 Scientific Coordinator, Principal Researcher, and Project Manager of the research program C.W.-SMILE, Panteion University, Athens, Greece

2 International Society for Quality of Life (ISQOLS), and the Community Indicators Consortium (CIC), Arlington, VA, USA

3 “C.W.-SMILE" program, Panteion University, Athens, Greece 


\section{Introduction}

The negative effects of the financial crisis of 2009-2018 on the Greek society as a whole can be reflected, to a large extent, in the rapid deterioration of child wellbeing in the country (Bougioukos \& Fasoulis, 2012, 2013, 2014, 2015; Papanastasiou et al., 2016). What is more, according to UNICEF (2020b), the ongoing COVID-19 global health crisis is showing signs that children might become its biggest victims.

Child well-being is currently measured with many indicators, with the Middle Years Development Instrument (MDI) being the most common and up-to-date on a global level (Guhn et al., 2012; Schonert-Reichl et al., 2011, 2013). A number of other indicators have been developed, each approaching the subjective well-being of children differently and by stressing, in most cases, life satisfaction (Casas et al., 2013; Dinisman et al., 2012; Huebner \& Furlong, 2016; Llosada-Gistau et al., 2015; Montserrat et al., 2015a; Montserrat et al., 2015b; Savahl et al., 2017; Viñas et al., 2019). Additionally, Michalos et al. (2012) recently associated children's attitudes and behaviors to sustainable development. Apart from all these, a significant tool to record child well-being is UNICEF's MODA (Multidimensional Overlapping Deprivation Analysis) (Chzhen et al., 2018), which deals with child well-being as a multi-dimensional phenomenon, emphasizing the relevant articles in the Convention on the Rights of the Child (Chzhen \& de Neubourg, 2014). At the European level, MODA (EU-MODA) utilizes data from Eurostat's statistics on income and living conditions (EU-SILK) (Chzhen et al., 2016). According to Michalos and Land (2018), more emphasis must be placed on subjective indicators of well-being rather than on objective ones when policies are planned. However, none of the previously mentioned indicators are closely linked to the new form of child well-being deterioration, which appeared in Greece during its years of austerity (Leriou et al., 2021) or during the period of COVID-19.

At present, studies on the negative impact of the COVID-19 crisis on the wellbeing of children are being conducted all over the world, especially by UNICEF, the OECD, and the World Bank. In particular, according to UNICEF (2020a), "Globally, the number of children living in monetary poor households could increase by 142 million by the end of 2020." In addition, according to Fiala et al. (2021), “... there could be between 122 and 144 million additional children living in MPHs [in monetary poor households] by the end of 2020 (compared to 2019). Moreover, there could be between 80 and 144 million additional children in these circumstances by the end of 2021" (p. 162). Moreover, the OECD (2020, pp. 4-6) has turned attention towards children already living in poverty since, probably, they will be influenced more gravely by this crisis. Furthermore, the OECD (2020, pp. 15-20) stresses that the pandemic shall affect the well-being of children in terms of their education. School closures and the establishment of e-learning will impact students with parents of a low educational level who cannot support them sufficiently during home schooling and those lacking access to the necessary digital technologies (e.g., internet) or a desk and a quiet space for studying at their homes. OECD (2020, pp. 7-8) also notes the severe consequences of 
the pandemic on children's nutrition, stressing that even prior to the health crisis, a large number globally had serious problems in this aspect of child well-being. In this context, it encourages national governments to implement food assistance programs, taking into account that children have ceased to attend schools regularly; thus, they do not enjoy school meals anymore (OECD, 2020, pp. 21-22). According to the World Bank (Azevedo et al., 2020, pp. 20-25), the students of today shall have a bad quality of life in their adulthood as a consequence of facing a dramatic reduction of lifecycle earnings throughout their work life, due to lower levels of learning, lost months in school closures, or the potential of dropping out of school. In this light, the World Bank encourages national governments to build more equitable and resilient education systems, in order to facilitate students to learn at home, and offer equal opportunities to all children without exceptions to access them (Azevedo et al., 2020, pp. 31-32).

In Greece, the first COVID-19 case was confirmed on February 26, 2020. As part of measures to prevent further spread of COVID-19 infections, a nationwide lockdown was imposed by the Greek government on March 23, 2020. On that date, the cumulative number of confirmed COVID-19 cases was 624, whereas there were 15 deaths (WHO, 2021). All residents were asked to limit non-essential movement. Only individuals going to or from work, shopping for food or medicine, or visiting a doctor were allowed out and violations of the lockdown were subject to fines. The Greek government had already shut down all schools on March 11, 2020. Teachers and pupils had to continue their normal school activities through video-conferencing for a few hours every day. The nationwide lockdown was gradually lifted from May 4, and on that date, the cumulative number of confirmed COVID-19 cases was 2,628, with 144 deaths (WHO, 2021). On May 11, the 3rd grade high school pupils were allowed to return to their schools. A week later, all secondary education schools and on June 1, 2020, all primary education schools were re-opened. The lockdown helped keep COVID-19 cases and deaths in Greece at a very low level. Kousi et al. (2021) argue, "Greece's response to the pandemic has been characterized by efficiency, maturity and early actions..." (p. 12). This view is also shared by Ladi et al. (2021), who argue that Greece successfully managed the first phase of the COVID-19 crisis. However, the economic impact was harsh. On the second quarter of 2020, GDP fell by 13\% (Eurostat, 2021). Furthermore, according to a survey conducted across Greek cities just after the country's lockdown period in May 2020, stress and fear were increased for a large part of the survey participants (Vatavali et al., 2020). On the other hand, social activity was affected in two main ways: family activities were increased, while activities with friends were reduced, and there was also a slight but significant increase in cycling and walking.

The research paper by Leriou et al. (2021) introduces new indicators suitable to be applied in crises. Through these, multi-dimensional estimations on the geographical distribution of the new kind of deterioration of child well-being in the region of Attica, Greece, were presented for the first time. More specifically, it presented the results of the first round of an ongoing research on child well-being. One more research paper by the same authors (Leriou et al. 2022) followed, presenting the results of the second round of the research, pertaining to the 1st semester of the school year 2019-2020. 
In Greece, currently, there are no studies on the harmful effects of the COVID-19 pandemic on child well-being; this includes surveys conducted on a regional level and in a multi-dimensional manner. There are no statistical data, indicators, or measurements available relevant to the impact of this health crisis on the well-being of children living in the Regional Unit of Attica. This lack of data has clearly created a research gap (Leriou et al., 2021) that must be covered by new studies.

The main aim of this research paper is to present and discuss the results of the third round of the research related to the 2nd semester of 2019-2020 and, furthermore, of this specific school year as a whole. Its secondary aim is to investigate the impact of the COVID-19 crisis on child well-being in Attica, Greece, and propose an action plan in the light of the legal framework accordingly.

\section{Methodology}

\subsection{Instruments and Target Population}

The tool used to record child well-being (Leriou et al., 2021) is structured on indicators (Appendix, Fig. 1) and founded on the same theoretical framework as the first round of the research (Leriou et al., 2021), which is based on welfare economics; it was implemented on children belonging to three school categories: the 6th grade of elementary school (10-11 years old), the 3rd grade of junior high (13-14 years old), and the 3rd grade of high school (16-17 years old) since children of these levels have a broader perception. It includes six dimensions (synthetic indicators): the first three (D.1, D.2, D.3) pertain to economic well-being and the other three (D.4, D.5, D.6) to non-economic well-being (Appendix, Fig. 1). Every dimension has specific simple indicators (Appendix, Fig. 1), each of which corresponds to specific questions in the questionnaires, which were the survey's instruments (Leriou et al., 2021) through which the data were collected.

The questionnaire addressing junior high and high school students is identical, while elementary school students were asked fewer questions, as the questionnaire addressing children at a younger age had to be simpler (Leriou et al., 2021). The questions concerned the 2nd semester of the school year 2019-2020, the period when the pandemic broke out in Greece and the lockdown was imposed. The questionnaires related to this timeframe are identical with those of the school year 2018-2019 (i.e., the first round of the research) (Leriou et al., 2021) and those of the 1st semester of the school year 2019-2020 (i.e., the second round of the research). The answers to the questionnaires were rated in their majority with 0 or 1 (Leriou et al., 2021).

\subsection{Ethics and Funding}

The questionnaires along with the appropriate permission letters addressed to the parents were examined by specialists and approved by the Ethics and Conduct Committee of the Panteion University; they were also accepted by the Ministry of 
Education, which issued two licenses for carrying out the survey in the schools: one for primary and one for secondary institutions. The research received funding from the Hellenic Foundation for Research and Innovation (HFRI) and the General Secretariat for Research and Technology (GSRT) under grant agreement No. 1926.

\subsection{Sample}

A multi-stage sampling design was implemented to construct the students' sample similarly to the first round of the research (Leriou et al., 2021). In the third round, 560 students from 22 public schools and 3 support centers (SCs) of the organization, The Smile of the Child, participated (Appendix, Table 1). More specifically, $30.4 \%$ were students of elementary, $34.1 \%$ and $35.5 \%$ were adolescents of junior high and high school, respectively. Additionally, the majority of the study population was from the public schools $(81.6 \%)$.

In order to identify relatively socio-economically homogeneous groups of municipalities, a hierarchical cluster analysis (HCA) was applied to a set of six variables with municipality-level aggregate data obtained by the 2011 census (Leriou et al., 2021).

\subsection{Statistical Analysis}

The analysis is predominately based on the synthetic indicators 1, 3, 4, and 5 (CWG ${ }_{i}, \mathrm{CWE}_{i}, \mathrm{CWNE}_{i}$ ) (Leriou et al., 2021). Following the approach adopted by Eurostat, a threshold for the risk of lacking well-being was established for the overall score of the synthetic indicators of Personal General Child Well-Being. In other words, the threshold amounts to $60 \%$ of the median of the values of all the subjects of the entire sample in the synthetic indicator of Personal General Child Well-Being. This was applied for both economic and non-economic child well-being in the same manner (Leriou et al., 2021). Furthermore, the analysis is based on composite indicators 7, 8, 9, 10, 11, and 12 (CWT, $\mathrm{W}_{\mathrm{D}_{\mathrm{N}}, \mathrm{T}}, \mathrm{w}_{\mathrm{S}_{\mathrm{j}}, \mathrm{N}_{T}}, \mathrm{CWET}, \mathrm{CWNET}$ ) (Leriou et al., 2021). All the information relevant to the aforementioned indicators and the analysis strategy are displayed in Leriou et al. (2021).

Initially, the analysis is performed for the 2nd semester of the school year 2019-2020. Subsequently, it was performed on this school year as a whole, by taking into account the data of both its 1 st semester (Leriou et al. 2022) and 2nd semester.

\section{Results}

The results of the 2nd semester of the school year 2019-2020 are presented first, while the results of the whole school year follow. Subsequently, the results of the first semester (Leriou et al. 2022) and the second are compared, in order to reach conclusions on the impact of the COVID-19 crisis on child well-being. 


\subsection{Geographical Distribution of Children's Well-Being (2nd Semester 2019- 2020)}

On the basis of Synthetic Indicators 1, 2, 3, 4, and $5\left(\mathrm{CWG}_{i}, \mathrm{~W}_{\mathrm{D}_{\mathrm{N}}, \mathrm{i}}, \mathrm{w}_{\mathrm{S}_{\mathrm{j}}, \mathrm{N}_{\mathrm{i}}}, \mathrm{CWE}_{i}\right.$, $\mathrm{CWNE}_{i}, \mathrm{CWG}_{\mathrm{i}}$ ) (Leriou et al., 2021), the percentages of children below and above the threshold of being at risk of lacking general economic and non-economic wellbeing, by cluster, school level, and gender were estimated, for the period of the 2 nd semester of the school year 2019-2020. In other words, the geographical distribution of children's well-being in the region of Attica was monitored (Appendix, Fig. 2, 3, and 4). The results of the Pearson's chi-squared test are also included.

With regard to the 2nd semester of school year 2019-2020 and all the clusters (Appendix, Table 2), the percentage of children below the threshold is $7.5 \%$ in general, $14.9 \%$ in economic, and $10.0 \%$ in non-economic well-being. In particular, as far as economic well-being is concerned, the percentages below the threshold appear to be higher in this period in Clusters 7 (22.4\%), 3 (19.8\%), and 4 (18.6\%), while 6, 1 , and 2 present the lowest rates (Appendix, Fig. 3). In terms of non-economic wellbeing, the highest percentages of children below the threshold are found in Clusters 4, 1, 3, and 7 and the lowest in 5, 6, and 2 (Appendix, Fig. 4). In general well-being, the highest percentages of children below the threshold are in Cluster $4(11.0 \%)$, followed by 3,1 , and $7(8.5 \%, 7.1 \%$, and $6.1 \%$ respectively), while the lowest in 5 (0.0\%), 6 (3.6\%), and 2 (4.5\%) (Appendix, Fig. 2).

With regard to the percentages of students below the threshold in economic, non-economic, and general well-being by Attica's municipality clusters, the analysis shows that there are statistically significant differences only in economic well-being (Appendix, Table 2). Moreover, the percentages of students below the threshold in economic well-being vary widely, ranging from $0.0 \%$ in Cluster 6 to as high as around $22.4 \%$ in Cluster $7\left(\chi_{[6, \mathrm{~N}=556]}^{2}=17.529, p=0.008\right)$. In addition, the Pearson's chi-square tests within the school level sub-samples indicate that the shares of elementary and high school students above or below the economic wellbeing threshold are closely linked to the municipality cluster in which their home is located $\left(\chi_{[6, \mathrm{~N}=169]}^{2}=20.971, p=0.003\right)$ and $\left(\chi_{[6, \mathrm{~N}=196]}^{2}=13.429, p=0.036\right)$ respectively. Similarly, the percentages of girls above or below the economic wellbeing threshold are closely linked to the municipality cluster $\left(\chi_{[6, \mathrm{~N}=282]}^{2}=12.939\right.$, $p=0.043$ ). Several other well-being categories (Appendix, Table 2) fall into the marginal, statistically significant level $(p>0.05$ and $p<0.15)$.

The reasons for such differences in the economic well-being of students between municipality clusters are complex and specific to the socio-economic realities of each municipality cluster. To develop a better understanding of the different risks for the well-being of students per cluster, one has to focus on the percentage of those below the threshold in each simple indicator that comprises the economic, non-economic, and general well-being per dimension (Appendix, Table 4).

As far as economic well-being is concerned, the analysis shows (Appendix, Table 4) that household employment (D.3) is associated with Attica's municipality clusters $\left(\chi_{[6, \mathrm{~N}=508]}^{2}=16.994, p=0.009\right)$. The highest shares of jobless households in the students' sample were reported in Clusters 4 (21.8\%) and 3 (16.5\%), two 
densely populated clusters which are inhabited by almost $72 \%$ of Attica's population, with a predominance of mainly lower to middle-class households. In addition, the economic well-being dimension of nutrition (D.2) is associated statistically with the location of the students' homes $\left(\chi_{[6, \mathrm{~N}=543]}^{2}=20.507, p=0.002\right)$.

In non-economic well-being (Appendix, Table 4), D.5 is associated with the municipality cluster that students live in $\left(\chi_{[6, \mathrm{~N}=551]}^{2}=13.486, p=0.035\right)$. In relation to moral values, Cluster 1 is doing much better than any other cluster as less students are below the threshold $\left(\chi_{[6, \mathrm{~N}=534]}^{2}=33.105, p<0.001\right)$. On the other hand, moral education offered in schools on the islands and in the coastal municipalities of Cluster 5 reaches more students when compared to other clusters, for example, love of people $\left(\chi_{[6, \mathrm{~N}=507]}^{2}=17.931, p=0.006\right)$, animals $\left(\chi_{[6, \mathrm{~N}=509]}^{2}=17.326, p=0.008\right)$, nature $\left(\chi_{[6, \mathrm{~N}=527]}^{2}=17.084, p=0.009\right)$, and social solidarity $\left(\chi_{[6, \mathrm{~N}=349]}^{2}=16.551\right.$, $p=0.011)$.

In addition, several child well-being simple indicators of D.1, D.2, and D.6 fall into the statistically or the marginal statistically significant level (Appendix, Table 4).

\subsection{Results of Means Scores (2nd Semester of 2019-2020)}

Consequently, Table 5 (Appendix) displays the values of Composite Indicators 7, 8, 9, 10, 11, and 12 (CWT, $\mathrm{W}_{\mathrm{D}_{\mathrm{N}}, \mathrm{T}}, \mathrm{w}_{\mathrm{S}_{\mathrm{j}}, \mathrm{N}_{T}}, \mathrm{CWET}, \mathrm{CWNET}$ ) (Leriou et al., 2021) for the 2nd semester of the school year 2019-2020.

The processing of data based on Composite Indicators reveals that on the level of dimensions in the 2nd semester of the school year 2019--2020, in all clusters and the total of Attica, the most serious problem appears in two dimensions, more specifically, in 5 and 3 (Appendix, Table 5).

The results of the one-way ANOVA (Appendix, Table 5) show a statistically significant difference $\mathrm{F}(6,477)=2.190, p<0.05$ in the means of the clusters in Simple Indicator 7; $\mathrm{F}(6,324)=2.556, p<0.05$ in Simple Indicator 12; $\mathrm{F}(6,500)=2.617$, $p<0.05$ in Simple Indicator 13; $\mathrm{F}(6,502)=4.791, p<0.001$ in Simple Indicator $14 ; \mathrm{F}(6,520)=3.399, p<0.05$ in Simple Indicator $15 ; \mathrm{F}(6,527)=5.805, p<0.001$ in Simple Indicator 16; $\mathrm{F}(6,342)=2.838, p<0.05$ in Simple Indicator 17; and $\mathrm{F}(6,535)=2.123, p<0.05$ in Simple Indicator 18. Furthermore, statistical significances were found in Dimension $1, \mathrm{~F}(6,548)=2.741, p<0.05$; Dimension 2, $\mathrm{F}(6,536)=2.622, p<0.05$; Dimension 3, F(6,501) $=2.150, p<0.05$; and Dimension $5, \mathrm{~F}(6,544)=3.822, p<0.05$. Finally, a statistically significant difference in the means of the clusters was found in economic well-being, $\mathrm{F}(6,549)=4.010, p<0.05$; in non-economic well-being, $\mathrm{F}(6,553)=3.400, p<0.05$; and in general well-being, $\mathrm{F}(6,553)=4.943, p<0.001$ (Appendix, Table 5).

\subsection{Geographical Distribution of Children's Well-Being (School Year 2019-2020)}

On the basis of Synthetic Indicators 1, 2, 3, 4, and $5\left(\mathrm{CWG}_{i}, \mathrm{~W}_{\mathrm{D}_{\mathrm{N}}, \mathrm{i}}, \mathrm{w}_{\mathrm{S}_{\mathrm{j}}, \mathrm{N}_{\mathrm{i}}}, \mathrm{CWE}_{i}\right.$, $\mathrm{CWNE}_{i}, \mathrm{CWG}_{\mathrm{i}}$ ) (Leriou et al., 2021), the percentages of children below and above the threshold of being at risk of lacking general economic and 
non-economic well-being, by cluster, school level, and gender, were estimated for the school year 2019-2020. In other words, the geographical distribution of children's well-being in the region of Attica was monitored. Furthermore, the results of the Pearson's chi-squared test are included.

As far as the school year 2019-2020 and all clusters (Appendix, Table 6) are concerned, the percentage of all children below the threshold is $5.9 \%$ in general, $11.6 \%$ in economic, and $9.2 \%$ in non-economic well-being. In addition, the shares of all children at risk of lacking economic, non-economic, and general well-being are associated with the municipality cluster. In particular, as far as economic well-being is concerned, the percentages below the threshold appear to be higher in this period in Clusters $3(18.8 \%), 7(14.8 \%), 4(12.9 \%)$, and $1(10.0 \%)$, while Clusters $6(3.5 \%), 2(5.4 \%)$, and $5(7.7 \%)$ present the lowest rates $\left(\chi_{[6, N=1,725]}^{2}=40.866, p<0.001\right)$. In terms of non-economic well-being, the highest percentages of children below the threshold are found in Clusters 3,4 , and 6 , and the lowest in $2,5,1$, and $7\left(\chi_{[6, N=1,731]}^{2}=13.378, p=0.037\right)$. In general well-being, the highest percentages of children below the threshold $\left(\chi_{[6, \mathrm{~N}=1,731]}^{2}=22.012, p=0.001\right)$ are found in Cluster $3(10.4 \%)$, followed by 4,1 , and $7(6.5 \%, 5.0 \%$, and $4.3 \%$ respectively), while the lowest in $2(2.5 \%), 6$ $(2.9 \%)$, and $5(3.8 \%)$ (Appendix, Table 6).

Moreover, taking elementary school children into account, their economic well-being $\left(\chi_{[6, \mathrm{~N}=546]}^{2}=29.512, p<0.001\right)$ is associated with the municipality cluster (Appendix, Table 6). A higher representative number of elementary school children is below the economic well-being threshold in Cluster 3 (24.2\%), as compared to other municipality clusters.

Similarly, the economic well-being $\left(\chi_{[6, \mathrm{~N}=606]}^{2}=15.059, p=0.020\right)$ of junior high school children is associated with the municipality cluster (Appendix, Table 6). A higher share of junior high school children is below the economic well-being threshold in Cluster $3(19.2 \%)$, as compared to other municipality clusters.

Furthermore, regarding male students, their economic and general well-being are associated with the municipality cluster. A higher share of male students is below the economic well-being threshold in Clusters 3 (24.5\%), 7 (17.5\%) and $4(14.3 \%)$ as compared to other municipality clusters $\left(\chi_{[6, N=752]}^{2}=34.372\right.$, $p<0.001)$. In general well-being, the highest shares of at-risk male students are recorded in Clusters $3(11.5 \%)$ and $7(7.5 \%)\left(\chi_{[6, \mathrm{~N}=756]}^{2}=15.765, p=0.016\right)$.

Regarding female students, their economic and general well-being are also associated with the municipality cluster. Specifically, a higher share of female students is below the economic well-being threshold in Clusters 3 (12.7\%), $7(12.5 \%)$, and $4(11.6 \%)$ as compared to other municipality clusters $\left(\chi_{[6, N=894]}^{2}=15.423, p=0.017\right)$. In general well-being, the highest shares of at-risk male students $\left(\chi_{[6, \mathrm{~N}=895]}^{2}=17.065, p=0.010\right)$ are recorded in the same municipality clusters: Clusters $3(8.5 \%)$ and 4 (7.1\%) (Appendix, Table 6).

Several other well-being categories (Appendix, Table 6) fall into the marginal statistically significant level $(p>0.05$ and $p<0.15)$. 


\subsection{Principal Component Analysis (PCA) (School Year 2019-2020)}

A PCA was performed (Appendix), in order to confirm the aforementioned results. Figure 5 (Appendix) reveals the clusters recording the best and the worst results in well-being according to the linear combination of the components generated from the PCA (Table 7, Appendix). Figure 5 (Appendix) shows that the best results were found in Clusters 6, 5, and 2, while 3, 4, 7, and 1 are the worst. The aforesaid is confirmed by the prior analysis of general well-being since the clusters with the best and worst well-being concord with the results of the PCA.

\subsection{Results of Means Scores (School Year 2019-2020)}

The processing of data on the ground of Composite Indicators 7, 8, 9, 10, 11, and 12 (Leriou et al., 2021) reveals that with regard to the dimensions in all clusters and all of Attica, the most serious problem in the school year 2019-2020 appears in a dimension belonging to the non-economic aspect of well-being, which is Dimension 5 (Appendix, Table 8). The dimension that follows in the total of Attica belongs to the economic aspect of well-being, which is Dimension 3 (Appendix, Table 8).

The results of the one-way ANOVA (Appendix, Table 8) show a statistically significant difference $\mathrm{F}(6,1,649)=3.857, p<0.05$ in the means of the clusters in Simple Indicator 10; F $(6,1,466)=3.844, p<0.05$ in Simple Indicator 4; $\mathrm{F}(6$, $1,660)=5.725, p<0.001$ in Simple Indicator 2; F $6,1,599)=2.598, p<0.05$ in Simple Indicator $1 ; \mathrm{F}(6,1,544)=6.894, p<0.001$ in Simple Indicator 11; $\mathrm{F}(6$, $1,509)=3.047, p<0.05$ in Simple Indicator 5; F $6,1,507)=3.453, p<0.05$ in Simple Indicator 7; $\mathrm{F}(6,1,536)=2.434, p<0.05$ in Simple Indicator 8; $\mathrm{F}(6$, $1,487)=2.389, p<0.05$ in Simple Indicator 6; $\mathrm{F}(6,1,046)=2.293, p<0.05$ in Simple Indicator 12; $\mathrm{F}(6,1,602)=4.527, p<0.001$ in Simple Indicator 13; $\mathrm{F}(6$, $1,620)=6.649, p<0.001$ in Simple Indicator 14; $\mathrm{F}(6,1,638)=6.806, p<0.001$ in Simple Indicator 15; $\mathrm{F}(6,1,634)=6.564, p<0.001$ in Simple Indicator 16; $\mathrm{F}(6,1,085)=4.806, p<0.001$ in Simple Indicator 17; $\mathrm{F}(6,1,676)=3.337$, $p<0.05$ in Simple Indicator 18; and $\mathrm{F}(6,1,683)=6.174, p<0.001$ in Simple Indicator 20. Furthermore, statistical significances were found in Dimension 1, $\mathrm{F}(6,1,716)=8.121, p<0.001$; Dimension $2, \mathrm{~F}(6,1,667)=5.104, p<0.001$; Dimension 3, $\mathrm{F}(6,1,611)=6.471, p<0.001$; Dimension 5, $\mathrm{F}(6,1,707)=9.487$, $p<0.001$; and Dimension 6, F $(6,1,719)=3.355, p<0.05$. Finally, a statistically significant difference in the means of the clusters was found in economic well-being, $\mathrm{F}(6,1,718)=10.720, p<0.001$; in non-economic well-being, $\mathrm{F}(6$, $1,724)=6.927, p<0.001 ;$ and in general well-being, $\mathrm{F}(6,1,724)=12.449$, $p<0.001$ (Appendix, Table 8). 


\subsection{Comparison between the 1st and 2nd Semesters of School Year 2019-2020: The Impact of the COVID-19 Crisis}

A comparison of the results on the basis of Synthetic Indicators pertaining to the surveys conducted during both the first (round two of the research) and second semester (round three of the research) of the school year 2019-2020 follows. The results of the first semester are presented and discussed by Leriou et al. (2022).

The results of the Pearson's chi-squared tests show a significant statistical difference in the percentage of students below the economic well-being threshold by semester in the school year 2019-2020 $\left(\chi_{[1, \mathrm{~N}=1,715)}^{2}=8.897, p=0.003\right)$. As shown in Table 9 (Appendix), $10.0 \%$ of the students were at risk of lacking economic well-being in the 1 st semester. In the 2 nd semester, a sharp increase of 5 percentage points (from $10 \%$ to almost 15\%) (Appendix, Table 9) of the number of students at risk of lacking economic well-being is noted (Appendix, Fig. 6). Hence, the economic well-being of children deteriorated in the 2nd semester, during the COVID-19 crisis and the lockdown measures introduced by the government (Appendix, Fig. 6).

Similarly, the analysis shows a significant statistical difference $\left(\chi_{[1, \mathrm{~N}=1,731)}^{2}=3.857\right.$, $p=0.050)$ in the percentage of students below the general well-being threshold by semester in the school year 2019-2020 (Appendix, Table 9).

Further analysis shows a statistically significant difference between 1st and 2nd semesters in the percentage of elementary school students at risk of lacking economic well-being $\left(\chi_{[1, \mathrm{~N}=546]}^{2}=8.600, p=0.003\right)$ (Appendix, Table 10). The number of elementary school students facing financial risk nearly doubled in the 2nd semester of this year as compared to the 1 st. Smaller, but statistically significant differences in economic well-being between the two semesters of this year are also found within the subsamples of boys $\left(\chi_{[1, \mathrm{~N}=752]}^{2}=4.854, p=0.028\right)$ and, marginally $\left(\chi_{[1, \mathrm{~N}=894]}^{2}=3.760\right.$, $p=0.052$ ), of girls (Appendix, Table 10).

An analysis on the level of simple indicators and dimensions (Appendix, Table 11) shows a deterioration in the economic well-being of students in the 2 nd semester of 2019-2020 as compared to the 1st, mainly due to a sharp increase by 5 percentage points $\left(\chi_{[1, N=1,618]}^{2}=8.452, p=0.004\right)$ in the rate of unemployed parents/guardians (Appendix, Fig. 7). In addition, when the 2nd semester is compared to the 1st, the percentage of children below the threshold presents an increase in D.1 (5.8\%) (Appendix, Fig. 8), D.2 (4.2\%), and D.6 (3.8\%), which is statistically significant (Appendix, Table 11). The school semester is associated statistically with the number of students (significantly more in the 2nd semester) reporting extended power cuts in their houses $\left(\chi_{[1, N=1,606]}^{2}=6.233, p=0.013\right)$, staying away from their family house for an extensive period $\left(\chi_{[1, \mathrm{~N}=1,551)}^{2}=27.088, p<0.001\right)$, as well as to the lack of fresh fruits and vegetables in their daily diet $\left(\chi_{[1, \mathrm{~N}=1,514]}^{2}=10.640, p=0.001\right)$, and no holidays $\left(\chi_{[1, \mathrm{~N}=1,690]}^{2}=34.476, p<0.001\right)$. 


\section{Discussion}

The processing of data on the grounds of Synthetic Indicators 1, 3, 4, and 5 reveals that in the 2nd semester of the school year 2019-2020, the worst situation with regard to general child well-being is found in Clusters 4, 3, 1, and 7, and the best in Clusters 5, 6, and 2 .

The analysis of the survey data on the grounds of the synthetic indicators in the 2nd semester of this school year reveals pressing issues relevant to the well-being of students in Attica. With regard to economic well-being, the large number of jobless households in Attica is indicative on how much the parents' employment status was influenced by the lockdown measures implemented by the Greek government, in order to slowdown the spread of COVID-19. In non-economic wellbeing, the social distancing measures affected the well-being of students, as 4 out of 10 reported that they cannot play outdoors. Furthermore, bearing in mind that tackling the pandemic requires people showing a high level of social responsibility, the students' answers in the simple indicators of moral education (Dimension 5) show that the schools of all three levels and the Ministry of Education need to significantly re-examine their role and policies in relation to the moral education of students.

The processing of data on the grounds of Composite Indicators 7, 8, 9, 10, 11, and 12 reveals that in the 2nd semester of school year 2019-2020, with regard to the dimensions in all clusters and in all of Attica, the gravest problem appears mainly in two dimensions, more specifically, in "Education focused on cultivating virtues in the individual" and "Unemployment". This finding generates great concern for the sustainable development of the region in the future.

Regarding disparities in the well-being of students per municipality cluster, the analysis showed that the highest percentage of students at risk of lacking economic well-being are found in Attica's densely populated metropolitan areas of Clusters 3 and 4, inhabited by almost $72 \%$ of Attica's population and, interestingly, in Cluster 7, which consists of the richest municipalities of Attica. As far as Clusters 3 and 4 are concerned, this finding probably reflects the economic impact of the COVID-19 pandemic and the lockdown on private sector jobs, mainly in stores, restaurants, cafés, and other small businesses operating in these metropolitan areas. As far as Cluster 7 is concerned, this finding is not surprising since children of rich families attend private schools and the research was conducted in public schools. Therefore, the students living in Cluster 7, who participated in the survey, are likely to come from poorer families who live and work there. Particularly, elementary school children in this cluster are affected the most by poor economic conditions. A decreasing number of children consume fresh fruits and vegetables daily in Cluster 3 as compared to students in other municipality clusters. Perhaps this is also due to the impact of the COVID-19 pandemic and the lockdown, as people in the densely populated areas stopped visiting supermarkets as often as they did in the past and turned to foods they could store for a long time. The findings suggest that in affluent middle-class suburbia (Cluster 6 ) and in the island and coastal municipalities (Cluster 5), which are sparsely 
populated, the students' nutrition tends to be of a better quality. Interestingly, the lowest percentages of students below the threshold in most of the moral education (D.5) simple indicators are found in the coastal/island municipalities of Cluster 5 (Aegina island, etc.). Perhaps schools there prioritize more on activities that help children develop stronger social ties in their local communities, enjoy the natural environment, and interact with animals.

The processing of data on the grounds of Synthetic Indicators 1, 3, 4, and 5 reveals that for the school year 2019-2020, the worst situation with regard to general child well-being is found in clusters 3, 4, 1, and 7, and the best in Clusters 2, 6 , and 5. The PCA confirms these results. On the grounds of Composite Indicators $7,8,9,10,11$, and 12 , the data reveal that policies to combat raging unemployment and promote an education that cultivates in children not only skills but also values that will render them worthy people (Tasopoulos \& Leriou, 2014) need to be implemented. On these grounds, it is clear that issues found in D.3 and D.5 in the school year 2018-2019 (Leriou et al., 2021) also remain in 2019-2020, while Clusters 3 and 4 need more direct interventions in order to achieve the social protection of children.

In terms of synthetic indicators, the comparison of the two semesters indicates that during the 2 nd semester, the economic well-being of children deteriorated, especially in the elementary school category. Specifically, the increase in the percentage of Attica's students at risk of lacking economic well-being is sharp. Most likely, this can be attributed to the lockdown measures introduced due to the pandemic. This deterioration in the second semester as compared to the first is mainly due to a spike in students living in jobless households. As a consequence, more students reported that they had extended power cuts in their homes, that they stayed as guests away from home for extended periods, that they didn't have fresh fruits and vegetables in their daily diet, and neither holidays. The spike of unemployment of the parents shows that the Regional Unit of Attica has entered perhaps a recession with tragic consequences for child well-being. This signifies that measures must be assumed immediately to mitigate unemployment. However, it must be noted that the percentage of children lacking well-being due to the unemployment of the parents was already high in the 1st semester of the school year 2019-2020 and that the percentage sky-rocketed tragically during the 2nd. Therefore, it is evident that the impact of COVID-19 on child well-being in Attica is related to the rise of unemployment, to the increase of houses with power cuts, to children staying as guests or homelessness, and to nutrition, as far as fresh fruits and vegetables are concerned. These results-pursuant to the OECD warnings for the impact of the pandemic on children's nutrition-call for direct measures relevant to unemployment and nutrition, the latter becoming worse due to the rise of unemployment.

All these estimations reveal the impact of the universal crisis of COVID-19 on child well-being in the Regional Unit of Attica, Greece, for the first time (Appendix, Figs. 6, 7, and 8). Moreover, they demonstrate the geographical distribution and the multi-dimensional characteristics of child well-being in the region, in the 2nd semester of the school year 2019-2020 and the same year, as a whole. 


\subsection{Suggestions for Action Planning for the Social Protection of Children in the Light of COVID-19 Crisis}

The impact of the COVID-19 pandemic on child well-being is especially grave in its economic aspect, due to the significant deterioration in D.3, a dimension evidently influencing the other dimensions of economic well-being of children (i.e., D.1 and D.2) negatively. In this context, emergency policies for the social protection of children must be materialized, aiming at mitigating the tragic consequences of the pandemic in child well-being in the region of Attica. As the results of the comparison of the two semesters of the school year 2019-2020 reveal, these policies must aim at reducing unemployment in parents and improving living conditions at home and nutrition.

Generous, drastic measures, as those suggested by the OECD (2020), must be assumed in order to improve children's nutrition, which deteriorated due to the explosion of unemployment in parents of the region of Attica by almost 13 percentage points in relation to the 1st semester of the school year 2019-2020. In this context, foodstuffs must be exempted from VAT tax (OECD, 2020, pp. 21-22) on the basis of economic policy, or food used in school meals must be redistributed to reach children's houses (OECD, 2020, pp. 21-22) for the entire period that the schools remain closed either due to COVID-19 or holidays. NGOs active in child protection could offer their assistance in this redistribution.

Apart from said interventions that must be applied in order to tackle the consequences of the COVID-19 crisis on the well-being of children, policies must be assumed to improve D.5, which presents issues throughout the three rounds of the research. In order to improve education, which teaches individuals what kind of persons they ought to be, special vocational training workshops must be held for teachers (OECD, 2019a, p. 112), focusing on all areas of Attica.

\subsubsection{Suggestions for Action Planning on the Basis of the Legal Framework}

Furthermore, policy planning authorities should expand the practice of school meals from the elementary level to junior high and high schools. Moreover, these meals should be fully implemented in all schools, all classes, and all school levels-no child in Attica, without exceptions, should be deprived of free and unobstructed access to them. In order to implement this policy, significant funds must be ensured so as to cover the financial cost of the nutrition of all children of Attica without any exclusions, according to the international legal framework (see Articles 18 and 24 of the Convention on the Rights of the Child and Article 24 of the Charter of Fundamental Rights of the European Union) but also pursuant to the Constitution of Greece (Article 21, par. 1-3) that stipulates the protection of children. Specifically, measures concerning their nutrition and unobstructed growth are among the state's fundamental obligations. Unfortunately, issues always arise in times of economic crises, when nations are incapable to fulfil their obligations under conditions of sudden financial shifts. Greece, many years ago, has already assumed several social policy measures relevant to the well-being of children. However, the recent financial crisis (2009-2018) has reduced its capacity to intervene. The problems arising from 
the new crisis of the pandemic came to complement the already existing unfavorable economic situation. In other words, unemployment has afflicted a significant number of citizens who are currently jobless, and the result of this is clear in the necessity to offer nutritional services to all children without exceptions. Due to all these (i.e., circumstances of insuperable force due to the financial situation and the urgency of supporting the public interest in the context of a healthy diet and smooth development of children), this paper supports the notion that nations as Greece must receive aid, especially since the country has suffered a financial crisis for one decade. European funds can be allocated so as to fulfil the obligation of offering a good nutrition to children and adolescents. The relevant claim of Greece for financial aid to feed children is founded on the aforementioned provisions of EU, international, and national legislations.

\section{Conclusions}

In this paper, a group of indicators that conclude into cumulative multi-dimensional indicators of child well-being (Leriou et al., 2021) were applied for the third time in the Regional Unit of Attica so as to measure child well-being in the 2nd semester of the school year 2019-2020. This measurement is a continuation of the first and second carried out in the same region (Leriou et al., 2021; Leriou et al. 2022).

In particular, the present paper presents the results of the third round of the research but also of the school year 2019-2020 as a whole. In addition, the impact of the COVID-19 crisis on child well-being in the region of Attica was detected, and actions for the social protection of children were suggested. Moreover, the study revealed the multi-dimensional characteristics, the extent, and the geographical distribution of child well-being in the region, in the third round. More specifically, the results show that child well-being based on both economic and non-economic factors worsened during the 2nd semester of 2019-2020, as compared to the 1st of the same year, while the clusters that present the greatest deterioration in the school year 2019-2020 as a whole are Clusters 3, 4, 1, and 7, as confirmed by the PCA performed.

Since the high percentages of children at risk of lacking well-being in the dimension of unemployment reveal that the economy in the region of Attica has entered perhaps a deep recession, generous measures must be assumed immediately in order to mitigate the unemployment of parents and reinforce child well-being as far as the nutritional aspect is concerned. The country must also rely both on the international legal framework and the Greek Constitution in order to claim financial aid to support the nutrition of children and adolescents, due to the extraordinary condition of the COVID-19 crisis and the consequences of the financial crisis preceding it, in other words, circumstances of insuperable force.

In conclusion, this paper applies a multi-dimensional approach of child wellbeing in order to detect the impact of the COVID-19 crisis on the well-being of children. It also documents the children's quality of life prior and post the pandemic, and suggests measures to improve it. Future research efforts should to discuss broadly all 
findings of the impact of COVID-19, for more periods, in Attica and to include a justification of the results from a social framework.

Supplementary Information The online version contains supplementary material available at https://doi. org/10.1007/s12187-021-09910-4.

Acknowledgments We would like to thank Ilias Gountas and the foundation "The Smile of the Child" for their very helpful comments, suggestions and for many insightful remarks and discussions.

Funding The present paper was drawn up within the context of the research project "C.W. - SMILE". This project has received funding from the Hellenic Foundation for Research and Innovation (HFRI) and the General Secretariat for Research and Innovation (GSRI), under grant agreement No. 1926.

\section{Declarations}

Conflict of Interest/Competing Interest The authors have no competing interests to declare that are relevant to the content of this article.

\section{References}

Azevedo, J. P., Hasan, A., Goldemberg, D., Iqbal, S. A., \& Geven, K. (2020). Simulating the potential impacts of COVID-19 school closures on schooling and learning outcomes: A set of global estimates (Policy research working paper no. 9284). World Bank. https://openknowledge.worldbank. org/handle/10986/33945

Bougioukos, G., \& Fasoulis, V. (2012). The situation of children in Greece (in Greek). Hellenic National Committee, UNICEF.

Bougioukos, G., \& Fasoulis, V. (2013). The situation of children in Greece (in Greek). Hellenic National Committee, UNICEF.

Bougioukos, G., \& Fasoulis, V. (2014). The situation of children in Greece (in Greek). Hellenic National Committee, UNICEF.

Bougioukos, G., \& Fasoulis, V. (2015). The situation of children in Greece (in Greek). Hellenic National Committee, UNICEF.

Casas, F., Bello, A., González, M., \& Aligué, M. (2013). Children's subjective well-being measured using a composite index: What impacts Spanish first-year secondary education students' subjective well-being? Child Indicators Research, 6(3), 433-460. https://doi.org/10.1007/ s12187-013-9182-X

Chzhen, Y., \& de Neubourg, C. (2014). Multiple overlapping deprivation analysis for the European Union (EU-MODA) (No. WP-2014-01). Florence: UN. 10.18356/355832ee-en.

Chzhen, Y., de Neubourg, C., Plavgo, I., \& de Milliano, M. (2016). Child poverty in the European Union: The multiple overlapping deprivation analysis approach (EU-MODA). Child Indicators Research, 9(2), 335-356. https://doi.org/10.1007/s12187-015-9321-7

Chzhen, Y., Bruckauf, Z., Toczydlowska, E., Elgar, F. G., Moreno-Maldonado, C., Stevens, G. W. J. M., et al. (2018). Multidimensional poverty among adolescents in 38 countries: Evidence from the health behaviour in school-aged children (HBSC) 2013/14 study. Child Indicators Research, 11, 729-753. https://doi.org/10.1007/s12187-017-9489-0.

Dinisman, T., Montserrat, C., \& Casas, F. (2012). The subjective well-being of Spanish adolescents: Variations according to different living arrangements. Children and Youth Services Review, 34(12), 2374-2380. https://doi.org/10.1016/j.childyouth.2012.09.005

Eurostat. (2021). GDP and main components [Table NAMQ_10_GDP]. https://ec.europa.eu/eurostat/ databrowser/view/NAMQ_10_GDP_custom_625172/bookmark/table?lang=en\&bookmarkId= cc973343-52ce-4e97-82e6-5f8ec45bd81a. Accessed 20 Aug 2021

Fiala, O., Delamónica, E., Escaroz, G., Martinez, I. C., Espinoz-Delgado, J., \& Kielem, A. (2021). Children in monetary poor households: Baseline and COVID-19 impact for 2020 
and 2021. Economics of Disaster and Climate Change, 5, 161-176. https://doi.org/10.1007/ s41885-021-00086-3

Guhn, M., Schonert-Reichl, K. A., Gadermann, A. M., Marriott, D., Pedrini, L., Hymel, S., \& Hertzman, C. (2012). Well-being in middle childhood: An assets-based population-level research-to-action project. Child Indicators Research, 5(2), 393-418. https://doi.org/10.1007/ s12187-012-9136-8

Huebner, E. S., \& Furlong, M. (2016). Measuring students' well-being. In S. M. Suldo (Ed.), Promoting student happiness: Positive psychology interventions in schools. Guilford Publications.

Kousi, T., Mitsi, L. C., \& Simos, J. (2021). The early stage of COVID-19 outbreak in Greece: A review of the national response and the socioeconomic impact. International Journal of Environmental Research and Public Health, 18(1), 322. https://doi.org/10.3390/ijerph18010322

Ladi, S., Angelou, A., \& Panagiotatou, D. (2021). Regaining trust: Evidence-informed policymaking during the first phase of the Covid-19 crisis in Greece. South European Society and Politics, 1-26. https://doi.org/10.1080/13608746.2021.1983932

Leriou, E., Kazani, A., Kollias, A., \& Paraskevopoulou, C. (2021). Understanding and measuring child well-being in the region of Attica, Greece: Round one. Child Indicators Research, 14, 1-51. https://doi.org/10.1007/s12187-020-09770-4

Leriou, E., Kollias, A., \& Anastasopoulou, A. (2022). Understanding and measuring child well-being in the region of Attica, Greece: Round Two. Child Indicators Research, 15, 315-347. https://doi. org/10.1007/s12187-021-09863-8

Llosada-Gistau, J., Montserrat, C., \& Casas, F. (2015). The subjective well-being of adolescents in residential care compared to that of the general population. Children and Youth Services Review, 52, 150-157. https://doi.org/10.1016/j.childyouth.2014.11.007

Michalos, A. C., \& Land, K. C. (2018). Replies to our commentators. Social Indicators Research, 135(3), 1057-1078.

Michalos, A. C., Creech, H., Swayze, N., Kahlke, M. P., Buckler, C., \& Rempel, K. (2012). Measuring knowledge, attitudes and behaviours concerning sustainable development among tenth grade students in Manitoba. Social Indicators Research, 106(2), 213-238. https://doi.org/10.1007/ s11205-011-9809-6

Montserrat, C., Casas, F., \& Moura, J. F. (2015a). Children's subjective well-being in disadvantaged situations. In Theoretical and empirical insights into child and family poverty (pp. 111-126). Springer. https://doi.org/10.1007/978-3-319-17506-5_7.

Montserrat, C., Dinisman, T., Bălţătescu, S., Grigoraş, B. A., \& Casas, F. (2015b). The effect of critical changes and gender on adolescents' subjective well-being: Comparisons across 8 countries. Child Indicators Research, 8(1), 111-131. https://doi.org/10.1007/s12187-014-9288-9

OECD. (2020). Combatting COVID-19's effect on children. OECD Publishing. http://www.oecd.org/ coronavirus/policy-responses/combatting-covid-19-s-effect-on-children-2e1f3b2f/\#blocknotesd7e 5536

Papanastasiou, S., Ntafouli, M., \& Kourtidou, D. (2016). The situation of children in Greece. Children at risk.

Savahl, S., Casas, F., \& Adams, S. (2017). Children's subjective well-being: Multi-group analysis among a sample of children from two socio-economic status groups in the Western cape, South Africa. Child Indicators Research, 10(2), 473-488. https://doi.org/10.1007/s12187-016-9392-0

Schonert-Reichl, K. A., Rowcliffe, P., Jaramillo, A., Foulkes, K., Thomson, K., \& Goessling, K. (2011). Middle childhood inside and out: The psychological and social worlds of Canadian children ages 9-12, Full report. . http://earlylearning.ubc.ca/documents/247/

Schonert-Reichl, K. A., Guhn, M., Gadermann, A. M., Hymel, S., Sweiss, L., \& Hertzman, C. (2013). Development and validation of the middle years development instrument (MDI): Assessing children's well-being and assets across multiple contexts. Social Indicators Research, 114(2), 345369. https://doi.org/10.1007/s11205-012-0149-y

Tasopoulos, A., \& Leriou, E. (2014). A new multidimensional model of ethics educational impact on welfare. Journal of Neural Parallel and Scientific Computations, 22(4), 595-608 ISSN 1061-5369.

UNICEF. (2020a). Children in monetary poor households and COVID-19. Technical note. https:// data.unicef.org/resources/children-in-monetary-poor-households-and-covid-19/. Accessed 20 Nov 2020.

UNICEF. (2020b). COVID-19 and children. https://data.unicef.org/topic/covid-19-and-children/. Accessed 20 Aug 2021. 
Vatavali, F., Gareiou, Z., Kehagia, F., \& Zervas, E. (2020). Impact of COVID-19 on urban everyday life in Greece. Perceptions, experiences and practices of the active population. Sustainability, 12(22), 9410. https://doi.org/10.3390/su12229410.

Viñas, F., Casas, F., Abreu, D. P., Alcantara, S. C., \& Montserrat, C. (2019). Social disadvantage, subjective well-being and coping strategies in childhood: The case of northeastern Brazil. Children and Youth Services Review, 97, 14-21. https://doi.org/10.1016/j.childyouth.2017.06.012

WHO (World Health Organization). (2021). COVID-19 Global Data [Data set]. https://covid19.who.int/ WHO-COVID-19-globaldata.csv. Accessed 20 Aug 2021.

Publisher's Note Springer Nature remains neutral with regard to jurisdictional claims in published maps and institutional affiliations. 